\title{
Rendimento dos componentes não-carcaça de cordeiros alimentados com silagem de milho ou cana-de-açúcar e dois níveis de concentrado ${ }^{1}$
}

\section{Greicy Mitzi Bezerra Moreno², Américo Garcia da Silva Sobrinho², André Gustavo Leão, Henrique Leal Perez ${ }^{2}$, Cintia Maria Battiston Loureiro², Gener Tadeu Pereira ${ }^{2}$}

\footnotetext{
1 Pesquisa financiada pela Fapesp (Fundação de Amparo à Pesquisa do Estado de São Paulo).

2 Faculdade de Ciências Agrárias e Veterinárias - FCAV/Unesp, Jaboticabal, SP.

3 Universidade Federal da Bahia, Salvador, BA.
}

RESUMO - Objetivou-se avaliar o rendimento dos componentes não-carcaça de cordeiros terminados em confinamento recebendo dietas formuladas com silagem de milho ou cana-de-açúcar e dois níveis de concentrado. Utilizaram-se 32 cordeiros Ile de France, não-castrados, alimentados com silagem de milho ou cana-de-açúcar em duas relações volumoso:concentrado, 60:40 ou 40:60. Os cordeiros foram mantidos em confinamento até atingirem $32 \mathrm{~kg}$ de peso corporal (PCA), quando foram abatidos. Após a sangria, todos os constituintes não-carcaça (sangue, pele, cabeça, patas, rúmen, retículo, omaso, abomaso, intestino delgado, intestino grosso, baço, fígado, coração, pulmão com traqueia, pâncreas, rins com gordura perirrenal, gorduras omental e mesentérica) foram separados e pesados, calculando-se suas porcentagens em relação ao PCA. O conteúdo do trato gastrintestinal (TGI) foi maior nos cordeiros alimentados com cana-de-açúcar (15,17\%) e 60\% de volumoso (14,55\%); enquanto as gorduras omental e perirrenal foram maiores nos cordeiros que receberam silagem de milho, 0,53 e 0,63\%, respectivamente. A relação volumoso:concentrado e o tipo de volumoso afetaram as proporções de rúmen, omaso e intestino delgado em relação ao peso total do trato gastrintestinal. A relação volumoso:concentrado e o tipo de volumoso influenciam o conteúdo do trato gastrintestinal de cordeiros, afetando indiretamente os rendimentos de carcaça. O tipo de alimentação tem maior influência sobre as proporções dos órgãos responsáveis pela digestão e absorção de nutrientes. Os fatores que influenciam os componentes não-carcaça de cordeiros são variados e contraditórios, o que torna necessária a realização de mais pesquisas para incentivar sua utilização e, consequentemente, agregar valor aos sistemas de produção de carne ovina.

Palavras-chave: confinamento, nutrição, órgãos, ovinos, vísceras

\section{Non-carcass components yield of lambs fed corn silage or sugar cane under two levels of concentrate}

\begin{abstract}
The objective of this result was to evaluate the yields of non-carcass components of lambs finished in feedlot feeding on diets with corn silage or sugarcane under two levels of concentrate. Thirty-two non-castrated Ile de France lambs fed on corn silage or sugar cane with two roughage:concentrate ratios: 60:40 or 40:60. Lambs were confined until they reached $32 \mathrm{~kg}$ of body weight (BW), when they were slaughtered. After the bleeding, all non-carcass components (blood, skin, head, feet, rumen, reticulum, omasum, abomasum, small intestine, large intestine, spleen, liver, heart, lung with trachea, pancreas, kidneys with perirenal fat, omental and mesenteric fat) were separated and weighed, and their percentages were calculated in relation to the BW. The content of gastrointestinal tract was greater in lambs which fed on sugar cane $(15.17 \%)$ and $60 \%$ of roughage (14.55\%); while omental and kidney fats were greater in lambs that received corn silage, 0.53 and $0.63 \%$, respectively. The roughage:concentrate ratio and type of forage affected the proportions of rumen, omasum and small intestine in relation to the total weight of gastrointestinal tract. The roughage:concentrate ratio and type of forage influence the content of the gastrointestinal tract of lambs, indirectly affecting the carcass yields. The type of food has greater influence on the proportions of the organs responsible for digestion and absorption of nutrients. The factors that influence the non-carcass components of lambs are varied and contradictory, requiring more research that might encourage their use and, consequently, add more value to the production systems of sheep meat.
\end{abstract}

Key Words: feedlot, nutrition, organs, sheep, viscera

\section{Introdução}

Com o aumento da competitividade dos mercados, tornou-se necessário aproveitar os subprodutos gerados durante o processo produtivo, entre eles, os componentes não-carcaça, que são uma importante alternativa para aumentar a rentabilidade dos sistemas. Segundo Osório (1992), os componentes não-carcaça são definidos como os 
constituintes do peso de corpo vazio, com exceção da carcaça, ou seja, o conjunto de órgãos, vísceras e outros subprodutos obtidos após o abate dos animais. Em alguns países desenvolvidos, o interesse da indústria de carne pelos componentes não-carcaça é maior, de modo que os preços concorrem com os de carne (Moron-Ruenmayor \& Clavero, 1999).

Segundo Santos et al. (2005), individualmente, os órgãos e as vísceras tem baixo valor comercial, no entanto, se usados como matéria-prima na elaboração de pratos típicos ou embutidos, permitem agregar valor à unidade de produção ou de abate, por isso, é importante conhecer os rendimentos desses constituintes e suas possibilidades de utilização. Entre estes, as vísceras, o fígado, os rins e coração são utilizados principalmente no Nordeste do Brasil em pratos típicos da culinária regional, como a buchada e o sarapatel, que permitem aumentar a renda dos produtores. Segundo Costa et al. (2007), a comercialização desses componentes pode proporcionar até $57,5 \%$ de receita adicional em relação ao valor da carcaça.

Os órgãos e as vísceras, em comparação a outras partes do corpo do animal, apresentam diferentes velocidades de crescimento e são influenciados principalmente pela composição química da dieta e seu nível energético (Kamalzadeh et al., 1998). Além disso, o tipo de volumoso e a relação volumoso:concentrado podem afetar o desenvolvimento dos componentes não-carcaça, principalmente daqueles mais relacionados à digestão, como o rúmen e retículo.

Considerando o alto custo de produção de cordeiros em confinamento, especialmente com alimentação, o uso de volumosos como a cana-de-açúcar constitui ferramenta importante para reduzir os custos totais desta fase. Existem alguns poucos trabalhos para avaliação do efeito do uso da cana-de-açúcar na terminação de cordeiros e seus efeitos sobre o desempenho, as características de carcaça e os componentes não-carcaça (Mendes et al., 2008;
Okamoto et al., 2008; Moreno et al., 2010). Neste trabalho, objetivou-se avaliar os rendimentos dos componentes não-carcaça de cordeiros terminados em confinamento recebendo dietas contendo silagem de milho ou cana-deaçúcar em combinação a dois níveis de concentrado.

\section{Material e Métodos}

Foram utilizados 32 cordeiros Ile de France, machos nãocastrados, com peso inicial médio de 15 kg distribuídos em quatro dietas contendo: $60 \%$ de silagem de milho $+40 \%$ de concentrado; $60 \%$ de cana-de-açúcar $+40 \%$ de concentrado; $40 \%$ de silagem de milho $+60 \%$ de concentrado; e $40 \%$ de cana-de-açúcar $+60 \%$ de concentrado.

A cana-de-açúcar utilizada no experimento foi a variedade forrageira IAC 86-2480, proveniente do primeiro corte, colhida manualmente em dias alternados e armazenada em área coberta e picada imediatamente antes do fornecimento aos animais.

As dietas foram calculadas para atender as exigências preconizadas pelo NRC (1985) para cordeiros desmamados com ganhos de peso estimados em $300 \mathrm{~g} / \mathrm{dia}$ (Tabelas $1 \mathrm{e} 2$ ).

A alimentação foi fornecida às $7 \mathrm{~h}$ e às $17 \mathrm{~h}$, com controle diário, permitindo sobras de $20 \%$, e as pesagens dos animais eram realizadas semanalmente, após jejum de sólidos por 16 horas. Ao atingirem $32 \mathrm{~kg}$ de peso corporal, os cordeiros foram pesados e mantidos em jejum de sólidos por 16 horas. Previamente ao abate, foram novamente pesados para obtenção do peso corporal ao abate (PCA) e insensibilizados por eletronarcose, com descarga elétrica de $220 \mathrm{~V}$ por 10 segundos, seguida de sangria por meio da secção das veias jugulares e artérias carótidas.

Após a esfola e evisceração, todos os componentes não-carcaça (sangue, pele, cabeça, patas, rúmen, retículo, omaso, abomaso, intestino delgado, intestino grosso, baço, fígado, coração, pulmão com traqueia, pâncreas, rins com gordura perirrenal, gorduras omental (recobre os estômagos)

Tabela 1 - Composição químico-bromatológica e de energia metabolizável dos ingredientes das dietas experimentais (\% MS)

\begin{tabular}{lccc}
\hline Nutriente & Silagem de milho & Cana-de-açúcar & Farelo de soja \\
\hline Matéria seca (\%) & 29,30 & 26,48 & Milho moído \\
Matéria orgânica (\%) & 25,51 & 24,35 & 88,34 \\
Matéria mineral (\%) & 3,79 & 2,13 & 81,60 \\
Proteína bruta (\%) & 8,67 & 2,92 & 6,74 \\
Extrato etéreo (\%) & 3,02 & 0,43 & 49,06 \\
Lignina (\%) & 2,90 & 3,66 & 1,86 \\
Fibra em detergente neutro (\%) & 43,38 & 35,92 & 2,40 \\
Fibra em detergente ácido (\%) & 22,48 & 20,52 & 3,95 \\
Carboidratos totais (\%) & 84,52 & 94,52 & 14,60 \\
Carboidratos não-fibrosos (\%) & 41,14 & 58,60 & 10,20 \\
Energia metabolizável (Mcal/kg) & 4,04 & 3,76 & 42,34 \\
\hline
\end{tabular}

${ }^{1}$ Estimada de acordo com NRC (1989), em que EM = ED × 0,82. 
Tabela 2 - Composição em ingredientes, nutricional das dietas e energia metabolizável das dietas experimentais (\% MS)

\begin{tabular}{|c|c|c|c|c|}
\hline & \multicolumn{4}{|c|}{ Relação volumoso:concentrado } \\
\hline & $\begin{array}{c}60 \% \text { silagem de milho }+ \\
40 \% \text { concentrado }\end{array}$ & $\begin{array}{c}60 \% \text { cana-de-açúcar }+ \\
40 \% \text { concentrado }\end{array}$ & $\begin{array}{c}40 \% \text { silagem de milho }+ \\
60 \% \text { concentrado }\end{array}$ & $\begin{array}{c}40 \% \text { cana-de-açúcar }+ \\
60 \% \text { concentrado }\end{array}$ \\
\hline \multicolumn{5}{|l|}{ Composição em ingredientes } \\
\hline Silagem de milho & 60,00 & - & 40,00 & - \\
\hline Cana-de-açúcar & - & 60,00 & - & 40,00 \\
\hline Ureia & 1,00 & 1,00 & 0,20 & 1,00 \\
\hline Milho moído & 19,20 & 9,55 & 34,10 & 32,30 \\
\hline Farelo de soja & 17,40 & 27,65 & 23,30 & 24,30 \\
\hline Sal iodado & 0,30 & 0,20 & 0,30 & 0,30 \\
\hline Calcário calcítico & 1,30 & 0,60 & 1,30 & 1,20 \\
\hline Fosfato bicálcico & 0,30 & 0,50 & 0,30 & 0,40 \\
\hline Núcleo mineral ${ }^{1}$ & 0,50 & 0,50 & 0,50 & 0,50 \\
\hline \multicolumn{5}{|l|}{ Composição nutricional (\% MS) } \\
\hline Matéria seca & 53,71 & 52,37 & 65,83 & 64,59 \\
\hline Matéria orgânica & 94,33 & 95,48 & 94,19 & 94,74 \\
\hline Matéria mineral & 5,67 & 4,52 & 5,81 & 5,26 \\
\hline Proteína bruta & 18,61 & 19,61 & 20,33 & 20,35 \\
\hline Extrato etéreo & 3,09 & 1,15 & 3,15 & 2,00 \\
\hline Fibra em detergente neutro & 32,46 & 26,15 & 24,13 & 21,81 \\
\hline Fibra em detergente ácido & 15,22 & 14,62 & 11,73 & 10,96 \\
\hline Carboidratos totais & 72,63 & 74,73 & 70,70 & 72,39 \\
\hline Carboidratos não-fibrosos & 40,16 & 48,58 & 46,58 & 50,58 \\
\hline Nutrientes digestíveis totais & 80,70 & 63,00 & 82,00 & 70,08 \\
\hline Energia metabolizável (Mcal/kg) & 3,91 & 3,81 & 3,94 & 3,83 \\
\hline Cálcio & 0,74 & 0,65 & 0,75 & 0,81 \\
\hline Fósforo & 0,38 & 0,36 & 0,41 & 0,36 \\
\hline
\end{tabular}

${ }^{1}$ Núcleo mineral: zinco - 1.600 mg; cobre - 300 mg; manganês - 1.500 mg; ferro - 1.100 mg; cobalto - 10 mg; iodo - 27 mg; selênio - 22 mg.

e mesentérica (recobre os intestinos) foram separados e pesados, calculando-se suas porcentagens em relação ao peso corporal ao abate.

O trato gastrintestinal (TGI), composto pelos estômagos e intestinos, foi separado, e cada compartimento foi pesado cheio e vazio, para obtenção do peso corporal vazio (PCV = PCA - conteúdo gastrintestinal). Posteriormente, determinaram-se a porcentagem de cada compartimento do trato gastrintestinal em relação ao seu peso total e o rendimento verdadeiro ou biológico (RV), obtido pela relação entre o peso da carcaça quente e o peso corporal vazio (Sañudo \& Sierra, 1986).

O delineamento experimental foi o inteiramente casualizado em esquema fatorial $2 \times 2$, composto de dois volumosos e duas relações volumoso:concentrado. Os dados foram submetidos à análise de variância pelo procedimento GLM do pacote estatístico SAS (SAS, 1996) a 5\% de significância. Quando detectadas diferenças significativas entre as dietas para as diferentes variáveis em estudo, as mesmas foram comparadas pelo teste de Tukey, ao mesmo nível de significância. O modelo matemático utilizado foi:

$$
\mathrm{Y}_{\mathrm{ijk}}=\mu+\mathrm{R}_{\mathrm{i}}+\mathrm{V}_{\mathrm{j}}+\mathrm{RV} \mathrm{ijj}_{\mathrm{ij}}+\mathrm{e}_{\mathrm{ijk}},
$$

em que: $Y_{i j k}=$ valor observado da variável estudada no indivíduo k recebendo a relação volumoso:concentrado i e volumoso $\mathrm{j} ; \mu=$ média geral; $\mathrm{R}_{\mathrm{i}}=$ efeito da relação volumoso:concentrado $i$, variando de 1 (40:60) a 2 (60:40); $\mathrm{V}_{\mathrm{j}}=$ efeito do volumoso j, variando de 1 (cana-de-açúcar) a 2 (silagem de milho); $\mathrm{RV}_{\mathrm{ij}}=$ efeito da interação entre relação volumoso:concentrado e tipo de volumoso; $\mathrm{e}_{\mathrm{ijk}}=$ erro aleatório associado a cada observação.

\section{Resultados e Discussão}

O maior peso do trato gastrintestinal (TGI), de 2,02 kg, foi observado nos animais alimentados com a dieta com relação 40:60 (Tabela 3). Houve influência $(\mathrm{P}<0,05)$ do tipo de volumoso sobre o peso do corpo vazio (PCV), que foi maior para os animais alimentados com silagem de milho $(27,93 \mathrm{~kg})$, provavelmente devido ao menor peso do conteúdo do trato gastrintestinal (3,93 kg).

O peso dos componentes não-carcaça, que pode atingir 40 a $60 \%$ do peso ao abate, é influenciado por fatores como peso corporal, sexo, tipo de nascimento, genética, idade e alimentação (Carvalho et al., 2005a). Siqueira et al. (2001) avaliaram os componentes não-carcaça de cordeiros mestiços Ile de France $\times$ Corriedale terminados em confinamento e reportaram valor de $4,52 \mathrm{~kg}$ para peso do conteúdo do TGI, semelhante ao encontrado neste estudo. Entretanto, Carvalho et al. (2005b) testaram o efeito da 
suplementação em pasto de capim-tifton 85 sobre os componentes não-carcaça de cordeiros sem padrão racial definido e encontraram valores de $5,70 \mathrm{~kg}$ no peso do conteúdo do trato gastrintestinal, superior ao deste trabalho. Esses resultados comprovam que o sistema de alimentação e a relação volumoso:concentrado tem grande influência sobre os componentes não-carcaça, especialmente aqueles envolvidos na digestão e absorção de nutrientes.

Os pesos médios do aparelho respiratório (pulmão e traqueia) e coração foram de 0,6 e 0,18 kg, respectivamente, e isso indica que a alimentação não influenciou as proporções desses órgãos vitais. Segundo Péron et al. (1993) e Alves et al. (2003), diferentemente dos órgãos ligados à digestão e ao metabolismo dos alimentos, os rendimentos de órgãos vitais, como aparelho respiratório, cérebro e coração, não são influenciados pela composição da dieta, já que esses órgãos têm prioridade na utilização dos nutrientes, mantendo sua integridade independentemente do estado nutricional dos animais. Normalmente, os pesos dos componentes nãocarcaça desenvolvem-se de forma similar com o aumento do peso corporal do animal, mas não nas mesmas proporções, ou seja, ocorre queda nas porcentagens em relação ao peso do animal. Gastaldi et al. (2001) constataram aumento $(\mathrm{P}<0,05)$ na proporção de pele quando o peso de abate de cordeiros não-castrados $1 / 2$ Ile de France $\times 1 / 2$ Ideal foi de 30 para 34 kg, evidenciando a importância desses componentes na comercialização da carcaça.

Houve interação $(\mathrm{P}<0,05)$ das relações volumoso:concentrado e do tipo de volumoso para o peso corporal ao abate (PCA), o conteúdo do TGI, a gordura omental e dos rins com gordura perirrenal (Tabelas 4 e 5).

Apenas o tipo de volumoso na relação 60:40 promoveu diferença $(\mathrm{P}<0,05)$, uma vez que os animais alimentados com silagem de milho apresentaram maior peso corporal ao abate, de 32,32 kg. Essa interação não era esperada, já que os animais foram submetidos ao mesmo tempo de jejum e abatidos quando atingiram aproximadamente $32 \mathrm{~kg}$ de peso corporal, ou seja, foram dadas as mesmas condições de jejum e o peso de abate foi preestabelecido igualmente para todos os animais, o que não justificaria a ocorrência de diferenças significativas nesta variável. Este resultado provavelmente pode ser explicado pelo baixo coeficiente de variação deste parâmetro (1,98\%, Tabela 3) e pela ocorrência de maiores perdas no jejum dos animais alimentados com cana-de-açúcar, embora essas perdas normalmente sejam constantes ao longo do tempo.

Tabela 3 - Pesos dos componentes não-carcaça de cordeiros alimentados com silagem de milho ou cana-de-açúcar e duas relações volumoso:concentrado

\begin{tabular}{|c|c|c|c|c|c|c|}
\hline \multirow[t]{2}{*}{ Variável (kg) } & \multicolumn{2}{|c|}{ Relação volumoso:concentrado (R) } & \multicolumn{2}{|c|}{ Volumoso (V) } & \multirow{2}{*}{$\begin{array}{c}\text { Interação } \\
(\mathrm{R} \times \mathrm{V})\end{array}$} & \multirow[t]{2}{*}{ CV (\%) } \\
\hline & $40: 60$ & $60: 40$ & Cana-de-açúcar & Silagem de milho & & \\
\hline Peso ao abate & 31,58 & 31,58 & 31,30 & 31,86 & $0,0046 *$ & 1,98 \\
\hline Peso corpo vazio & 27,49 & 26,98 & $26,55 b$ & $27,93 a$ & 0,1667 & 2,07 \\
\hline Rendimento verdadeiro (\%) & 57,43 & 57,32 & 57,28 & 57,48 & 0,4539 & 2,35 \\
\hline Trato gastrintestinal & $2,02 \mathrm{a}$ & $1,83 b$ & 1,87 & 1,99 & 0,2526 & 7,81 \\
\hline Conteúdo do trato gastrintestinal & $4,08 b$ & $4,59 a$ & $4,75 a$ & $3,93 b$ & $0,0192 *$ & 10,97 \\
\hline Sangue & 1,17 & 1,02 & 1,03 & 1,16 & 0,5392 & 21,09 \\
\hline Pele & 3,05 & 3,08 & 3,03 & 3,09 & 0,9495 & 6,81 \\
\hline Patas & 0,84 & 0,83 & 0,84 & 0,83 & 0,7293 & 3,80 \\
\hline Cabeça & 1,68 & 1,72 & 1,73 & 1,67 & 0,4754 & 5,22 \\
\hline Gordura mesentérica & 0,16 & 0,16 & 0,16 & 0,17 & 0,3594 & 23,11 \\
\hline Gordura omental & 0,13 & 0,16 & $0,12 b$ & $0,17 \mathrm{a}$ & $0,0021 *$ & 23,96 \\
\hline Rins e gordura perirrenal & 0,18 & 0,18 & $0,16 b$ & $0,20 \mathrm{a}$ & $0,0038 *$ & 13,79 \\
\hline Coração & 0,18 & 0,18 & 0,17 & 0,18 & 0,8080 & 10,28 \\
\hline Pulmão e traqueia & 0,63 & 0,57 & 0,57 & 0,63 & 0,2462 & 14,59 \\
\hline Pâncreas & 0,04 & 0,05 & 0,04 & 0,05 & 0,8408 & 24,07 \\
\hline Baço & 0,06 & 0,05 & 0,05 & 0,06 & 0,7995 & 15,89 \\
\hline Fígado & 0,49 & 0,47 & 0,44 & 0,51 & 0,6839 & 24,77 \\
\hline
\end{tabular}

Médias seguidas por letras diferentes na linha diferem $(\mathrm{P}<0,05)$ pelo teste Tukey.

$\mathrm{CV}=$ coeficiente de variação; * significativo a $5 \%$ de probabilidade.

Tabela 4 - Desdobramento da interação para peso corporal ao abate de cordeiros

\begin{tabular}{|c|c|c|c|}
\hline \multirow[t]{2}{*}{ Relação volumoso:concentrado } & \multicolumn{2}{|c|}{ Volumoso } & \multirow[t]{2}{*}{ CV $(\%)$} \\
\hline & Cana-de-açúcar & Silagem de milho & \\
\hline $40: 60$ & $31,76 \mathrm{Aa}$ & $31,40 \mathrm{Aa}$ & 2,98 \\
\hline $60: 40$ & $30,84 \mathrm{Ba}$ & $32,32 \mathrm{Aa}$ & 2,45 \\
\hline CV ( \%) & 3,10 & 2,57 & \\
\hline
\end{tabular}

Médias seguidas pela mesma letra maiúscula na linha e mesma letra minúscula na coluna não diferem $(\mathrm{P}>0,05)$ pelo teste Tukey.

$\mathrm{CV}=$ coeficiente de variação. 
Tabela 5 - Desdobramento da interação para pesos do conteúdo do trato gastrintestinal, gordura omental e rins com gordura perirrenal de cordeiros

\begin{tabular}{|c|c|c|c|c|c|c|}
\hline \multirow{3}{*}{$\begin{array}{l}\text { Relação } \\
\text { volumoso:concentrado }\end{array}$} & \multicolumn{2}{|c|}{ Conteúdo do trato gastrintestinal } & \multicolumn{2}{|c|}{ Gordura omental } & \multicolumn{2}{|c|}{ Rins com gordura } \\
\hline & \multicolumn{2}{|c|}{ Volumoso } & \multicolumn{2}{|c|}{ Volumoso } & \multicolumn{2}{|c|}{ Volumoso } \\
\hline & Cana-de-açúcar & Silagem de milho & Cana-de-açúcar & Silagem de milho & Cana-de-açúcar & Silagem de milho \\
\hline $40: 60$ & 4,77Aa & $3,40 \mathrm{Bb}$ & $0,13 \mathrm{Aa}$ & $0,12 \mathrm{Ab}$ & $0,18 \mathrm{Aa}$ & $0,18 \mathrm{Aa}$ \\
\hline $60: 40$ & 4,73Аа & $4,64 \mathrm{Aa}$ & $0,11 \mathrm{Ba}$ & $0,21 \mathrm{Aa}$ & $0,14 \mathrm{Ba}$ & $0,22 \mathrm{Aa}$ \\
\hline
\end{tabular}

Médias seguidas pela mesma letra maiúscula na linha e mesma letra minúscula na coluna não diferem $(\mathrm{P}>0,05)$ pelo teste Tukey.

Os animais alimentados com cana-de-açúcar na relação volumoso:concentrado 40:60 apresentaram maior peso do conteúdo do trato gastrintestinal, 4,77 kg (Tabela 5), o que provavelmente ocorreu devido à menor digestibilidade da fibra da cana-de-açúcar, ocasionando maior tempo de retenção desse volumoso no trato gastrintestinal dos animais e maior desenvolvimento do mesmo.

$\mathrm{O}$ fato de não ter ocorrido diferença $(\mathrm{P}>0,05)$ no peso do trato gastrintestinal entre as dietas com cana-de-açúcar (4,75 kg) sugere que, mesmo em menores proporções, a cana-de-açúcar causa regulação no consumo, devido ao maior enchimento do rúmen. Entre os animais alimentados com silagem de milho, o maior peso do conteúdo do trato gastrintestinal foi obtido com a relação de volumoso:concentrado de 60:40, de 4,54 kg, o que pode ser explicado pela maior quantidade de volumoso na dieta.

Os pesos de gordura omental e de rins com gordura perirrenal foram maiores nos animais alimentados com $60 \%$ de silagem de milho na dieta, de 0,21 e 0,22 kg, respectivamente. Kozloski (2002) afirmou que o maior nível de concentrado na dieta aumenta a concentração de ácido propiônico no rúmen e diminui a relação acetato:propionato, resultando em maior disponibilidade de energia na forma de glicose, o que favorece a lipogênese e consequente deposição de gordura visceral. Entretanto, os resultados encontrados neste trabalho contrariam os desse autor, já que maior peso de gordura omental foi observado nos animais alimentados com as dietas com menor teor de concentrado e não foram observadas diferenças $(\mathrm{P}>0,05)$ para as gorduras perirrenal nas duas relações volumoso:concentrado estudadas.

O maior peso de gordura omental encontrado nos animais alimentados com $60 \%$ de silagem de milho e $40 \%$ de concentrado pode ser explicado pela alta quantidade de grãos nesta dieta, proveniente da silagem de milho e do concentrado, que aumenta consideravelmente a deposição de gordura omental. Segundo Alonso et al. (1998) e Atti (2000), dietas com altos teores de proteína, como as utilizadas neste trabalho, podem aumentar a atividade da microbiota ruminal, sua concentração na corrente sanguínea e consequente absorção, ocasionado maior deposição de gordura em torno do retículo-rúmen. No entanto, é importante ressaltar que o acúmulo de grandes quantidades de gordura interna não é desejável, pois há aumento das exigências de energia para mantença, devido à maior taxa metabólica do tecido adiposo, e há desperdício da energia fornecida pela dieta, já que a gordura interna não é aproveitada para consumo humano (Ferreira et al., 2000).

Analisando os componentes não-carcaça de cordeiros submetidos a diferentes sistemas de alimentação (em confinamento, suplementação em pastagem nativa ou com acesso a creep feeding), Carvalho et al. (2005a) notaram que, numericamente, o confinamento proporcionou maiores proporções de gorduras interna e renal (1,61 e 0,68\%, respectivamente) em comparação à suplementação em pastagem nativa (1,02 e 0,35\%) ou com acesso a creep feeding (1,00 e 0,38\%), respectivamente, o que pode ser explicado pelo maior consumo diário de energia e pelo menor gasto energético dos cordeiros confinados. De acordo com Jenkins (1993), as mudanças na alimentação durante o período de crescimento do animal alteram a ingestão e digestibilidade, podendo influenciar no desenvolvimento dos órgãos.

A porcentagem do conteúdo do trato gastrintestinal foi influenciada $(\mathrm{P}<0,05)$ pela relação volumoso:concentrado e pelo tipo de volumoso, pois foi maior na relação 60:40 e nos animais alimentados com cana-de-açúcar, de 14,55 e 15,17\%, respectivamente (Tabela 6). Esses valores foram superiores à média de 13,40\% reportada por Siqueira et al. (2001) ao estudarem os componentes não-carcaça de cordeiros Ile de France $\times$ Corriedale abatidos com diferentes pesos. Segundo esses autores, o conteúdo do trato gastrintestinal tem grande participação nos componentes não-carcaça e pode ser influenciado pelos alimentos, que apresentam diferentes velocidades de passagem.

A porcentagem de sangue foi de $3,48 \%$ em relação ao peso corporal ao abate, semelhante ao valor médio encontrado na literatura, entre 3,0 e 4,0\% para ovinos. A quantidade de sangue eliminada durante o abate pode informar sobre a eficiência de sangria, pois, segundo Forrest et al. (1979), mesmo em condições eficientes, só se consegue eliminar entre 50 e $60 \%$ do volume total de sangue do animal, pois o restante fica retido nos órgãos vitais. 
Tabela 6 - Porcentagens (\%) dos componentes não-carcaça em relação ao peso corporal ao abate de cordeiros

\begin{tabular}{|c|c|c|c|c|c|c|}
\hline \multirow[t]{2}{*}{ Variável (kg) } & \multicolumn{2}{|c|}{ Relação volumoso:concentrado (R) } & \multicolumn{2}{|c|}{ Volumoso (V) } & \multirow{2}{*}{$\begin{array}{c}\text { Interação } \\
(\mathrm{R} \times \mathrm{V})\end{array}$} & \multirow[t]{2}{*}{ CV (\%) } \\
\hline & $40: 60$ & $60: 40$ & Cana-de-açúcar & Silagem de milho & & \\
\hline Peso corporal ao abate (kg) & 31,58 & 31,58 & 31,30 & 31,86 & $0,0046 *$ & 1,98 \\
\hline Conteúdo do trato gastrintestinal & $12,92 b$ & $14,55 \mathrm{a}$ & $15,17 \mathrm{a}$ & $12,30 \mathrm{~b}$ & 0,0484 & 10,24 \\
\hline Sangue & 3,72 & 3,24 & 3,30 & 3,66 & 0,3911 & 21,70 \\
\hline Pele & 9,65 & 9,75 & 9,69 & 9,71 & 0,4244 & 7,25 \\
\hline Gordura mesentérica & 0,52 & 0,52 & 0,50 & 0,54 & 0,5085 & 24,16 \\
\hline Gordura omental & 0,41 & 0,50 & $0,38 \mathrm{~b}$ & $0,53 a$ & $0,0027 *$ & 22,81 \\
\hline Rins e gordura perirrenal & 0,58 & 0,57 & $0,51 b$ & $0,63 a$ & $0,0126^{*}$ & 14,67 \\
\hline Coração & 0,56 & 0,56 & 0,56 & 0,56 & 0,7398 & 10,68 \\
\hline Pulmão e traqueia & 1,98 & 1,80 & 1,82 & 1,96 & 0,4575 & 14,42 \\
\hline Pâncreas & 0,14 & 0,15 & 0,14 & 0,15 & 0,9509 & 24,73 \\
\hline
\end{tabular}

Médias seguidas por letras diferentes na linha diferem $(\mathrm{P}<0,05)$ pelo teste Tukey.

* significativo a $5 \%$ de probabilidade.

A pele correspondeu a $9,70 \%$ do peso corporal dos cordeiros, inferior apenas à porcentagem de conteúdo de trato gastrintestinal. Destaca-se que a pele e o conteúdo do trato gastrintestinal são os componentes não-carcaça que contribuem com maior porcentagem em relação ao peso corporal ao abate dos ovinos, e que podem sofrer grandes variações. Além disso, a pele é o componente mais importante e mais valorizado, atingindo entre 10 e $20 \%$ do valor do animal (Fraser \& Stamp, 1989). De acordo com Siqueira et al. (2001), o peso da pele pode variar de acordo com as diferentes densidades e os diâmetros de fibra e a altura das mechas, no caso de animais lanados, enquanto o peso do conteúdo gastrintestinal é influenciado pelo tipo de dieta, sua velocidade de passagem, tempos de jejum, entre outros.

A relação volumoso:concentrado influenciou $(\mathrm{P}<0,05)$ a porcentagem de baço, que foi maior na relação 40:60. Considerando que o baço, juntamente com fígado e rins, é um órgão de elevada taxa metabólica, o maior nível de concentrado pode ter proporcionado o maior percentual desse órgão nos cordeiros alimentados com esta dieta. Medeiros et al. (2008), avaliando o efeito dos níveis de concentrado sobre os componentes não-carcaça de ovinos Morada Nova, observaram aumento linear dos pesos de fígado e vesícula biliar com o aumento do nível de concentrado na dieta, o que não ocorreu com demais órgãos (pulmões + traqueia, coração, baço, pâncreas, diafragma, aparelho reprodutivo, timo e rins), comprovando que esses órgãos estão mais relacionados ao peso corporal e à maturidade dos animais.

Não houve interação $(\mathrm{P}>0,05)$ entre as relações volumoso:concentrado e o tipo de volumoso utilizado para pesos e proporções dos constituintes do trato gastrintestinal, expressos em porcentagem do peso corporal ao abate e do trato gastrintestinal total (Tabela 7).

Em relação ao peso dos componentes, houve diferença $(\mathrm{P}<0,05)$ apenas para o peso do intestino delgado, que foi influenciado pela relação volumoso:concentrado e pelo tipo de volumoso. Consequentemente, a proporção de intestino delgado também foi influenciada, pois foi maior na relação 40:60 e quando utilizada silagem de milho como volumoso, de 2,32 e 2,25\%, respectivamente. O intestino delgado tem função de absorção de nutrientes e seu tamanho é proporcional ao tamanho do corpo do animal e ao tipo de alimentação, principalmente em relação ao nível de fibra na dieta (Furlan et al., 2006). Além disso, segundo esses autores, a presença de grande quantidade de nutrientes provenientes de dietas balanceadas promove maior desenvolvimento dos intestinos, pois os nutrientes que escapam da fermentação ruminal induzem o processo mitótico das vilosidades intestinais.

A relação volumoso:concentrado e o tipo de volumoso afetaram as proporções de rúmen, omaso e intestino delgado em relação ao peso total do trato gastrintestinal. Nos cordeiros alimentados com a dieta com $60 \%$ de volumoso, o rúmen e o omaso corresponderam a 29,70 e 4,47\% do seu trato gastrintestinal, respectivamente, enquanto esses mesmos constituintes corresponderam a 30,06 e 4,50\% do trato gastrintestinal dos cordeiros alimentados com canade-açúcar. Apesar de as dietas experimentais serem isoproteicas e isoenergéticas, houve maior desenvolvimento do rúmen e omaso nos animais alimentados com mais volumoso na dieta e quando utilizada a cana-de-açúcar como volumoso. Estes resultados estão de acordo com relatos de Alves et al. (2003) e Medeiros et al. (2008) de que dietas com menor densidade energética apresentam maiores 
Tabela 7 - Pesos e porcentagens dos componentes do trato gastrintestinal em relação ao peso corporal ao abate e ao trato gastrintestinal total de cordeiros

\begin{tabular}{|c|c|c|c|c|c|c|}
\hline \multirow[t]{2}{*}{ Variável (kg) } & \multicolumn{2}{|c|}{ Relação volumoso:concentrado (R) } & \multicolumn{2}{|c|}{ Volumoso (V) } & \multirow{2}{*}{$\begin{array}{c}\text { Interação } \\
(\mathrm{R} \times \mathrm{V})\end{array}$} & \multirow[t]{2}{*}{ CV $(\%)$} \\
\hline & $40: 60$ & $60: 40$ & Cana-de-açúcar & Silagem de milho & & \\
\hline \multicolumn{7}{|l|}{ Rúmen } \\
\hline $\mathrm{kg}$ & 0,55 & 0,54 & 0,56 & 0,53 & 0,6551 & 9,92 \\
\hline$\%$ peso ao abate & 1,73 & 1,71 & 1,78 & 1,67 & 0,8338 & 9,72 \\
\hline$\%$ trato gastrintestinal & $27,00 \mathrm{~b}$ & $29,70 \mathrm{a}$ & $30,06 a$ & $26,65 b$ & 0,3159 & 5,90 \\
\hline \multicolumn{7}{|l|}{ Retículo } \\
\hline $\mathrm{kg}$ & 0,08 & 0,08 & 0,08 & 0,08 & 0,8697 & 16,46 \\
\hline$\%$ peso ao abate & 0,27 & 0,25 & 0,26 & 0,26 & 0,6256 & 17,35 \\
\hline$\%$ trato gastrintestinal & 4,18 & 4,34 & 4,30 & 4,21 & 0,4958 & 18,13 \\
\hline \multicolumn{7}{|l|}{ Omaso } \\
\hline $\mathrm{kg}$ & 0,07 & 0,08 & 0,08 & 0,07 & 0,8320 & 13,38 \\
\hline$\%$ peso ao abate & 0,23 & 0,26 & 0,26 & 0,23 & 0,7940 & 13,69 \\
\hline$\%$ trato gastrintestinal & $3,66 b$ & $4,47 \mathrm{a}$ & $4,50 \mathrm{a}$ & $3,63 b$ & 0,5214 & 13,51 \\
\hline \multicolumn{7}{|l|}{ Abomaso } \\
\hline $\mathrm{kg}$ & 0,15 & 0,13 & 0,13 & 0,15 & 0,9080 & 13,45 \\
\hline$\%$ peso ao abate & 0,47 & 0,42 & 0,43 & 0,47 & 0,7645 & 13,13 \\
\hline$\%$ trato gastrintestinal & 7,38 & 7,32 & 7,20 & 7,49 & 0,5833 & 13,01 \\
\hline \multicolumn{7}{|l|}{ Intestino delgado } \\
\hline $\mathrm{kg}$ & $0,73 a$ & $0,61 \mathrm{~b}$ & $0,62 \mathrm{~b}$ & $0,72 \mathrm{a}$ & 0,1017 & 11,93 \\
\hline$\%$ peso ao abate & $2,32 \mathrm{a}$ & $1,91 \mathrm{~b}$ & $1,98 b$ & $2,25 \mathrm{a}$ & 0,2484 & 11,73 \\
\hline$\%$ trato gastrintestinal & $36,21 \mathrm{a}$ & $32,75 b$ & $33,07 b$ & $35,89 a$ & 0,0940 & 6,97 \\
\hline \multicolumn{7}{|l|}{ Intestino grosso } \\
\hline $\mathrm{kg}$ & 0,44 & 0,39 & 0,39 & 0,44 & 0,8089 & 13,15 \\
\hline$\%$ peso ao abate & 1,39 & 1,24 & 1,25 & 1,38 & 0,8509 & 13,36 \\
\hline$\%$ trato gastrintestinal & 21,57 & 21,42 & 20,86 & 22,13 & 0,6151 & 10,08 \\
\hline
\end{tabular}

Médias seguidas por letras diferentes na linha diferem $(\mathrm{P}<0,05)$ pelo teste Tukey.

teores de fibra e menor digestibilidade, resultando em maior tempo de retenção do alimento no retículo-rúmen e omaso, proporcionando-lhe maior desenvolvimento.

A importância dos componentes não-carcaça não está relacionada apenas à possibilidade de aumentar o retorno econômico no momento da comercialização dos produtos oriundos da ovinocultura, mas também ao alimento ou às matérias-primas que se perdem e que poderiam colaborar na melhoria do nível nutricional de populações (Yamamoto, 2004). Em sistemas de produção de pequenos ruminantes, o aproveitamento dos componentes nãocarcaça tem importância maior que em outros sistemas de produção animal, tendo em vista o grande número de pratos culinários preparados com os órgãos dessas espécies e que podem gerar para o produtor uma fonte de renda adicional (Cezar \& Sousa, 2007).

\section{Conclusões}

A relação volumoso:concentrado e o tipo de volumoso influenciam o conteúdo do trato gastrintestinal de cordeiros, afetando indiretamente os rendimentos de carcaça. O tipo de alimentação tem maior influência sobre as proporções dos órgãos responsáveis pela digestão e absorção de nutrientes. Os fatores que influenciam os não-componentes da carcaça de cordeiros são variados e contraditórios, tornando necessária a realização de mais pesquisas para incentivar sua utilização e agregar valor aos sistemas de produção de carne ovina.

\section{Agradecimentos}

À Fundação de Amparo à Pesquisa do Estado de São Paulo (FAPESP), pelo apoio financeiro dado a esta pesquisa.

\section{Referências}

ALONSO, T.M.; MANTECÓN, A.R.; MADRIGAL, T.C. Rendimiento de la canal, quinto quarto y despiece de corderos de raza Churra sometidos a distintas estrategias de alimentación. Archivos de Zootecnia, v.47, n.177, p.13-84, 1998.

ALVES, K.S.; CARVALHO, F.F.R.; FERREIRA, M.A. et al. Níveis de energia em dietas para ovinos Santa Inês: características de carcaça e constituintes corporais. Revista Brasileira de Zootecnia, v.32, n.6, p.1927-1936, 2003 (Supl. 2).

ATTI, N.; NOZIERE, P.; DOREAN, M. et al. Effects of underfeeding and referring on offals weight in Barbary ewes. Small Ruminant Research, v.38, p.37-43, 2000.

CARVALHO, S.; SILVA, M.F.; CERUTTI, R. et al. Desempenho e componentes do peso vivo de cordeiros submetidos a diferentes sistemas de alimentação. Ciência Rural, v.35, n.3, p.650-655, 2005a. 
CARVALHO, S.; VERGUEIRO, A.; KIELING, R. Avaliação da suplementação concentrada em pastagem de Tifton-85 sobre os componentes não carcaça de cordeiros. Ciência Rural, v.15, n.2, p.435-439, 2005b.

CEZAR, M.F.; SOUSA, W.H. Carcaças ovinas e caprinas: obtenção, avaliação e classificação. Uberaba: Editora Agropecuária Tropical, 2007. 147p.

COSTA, R.G.; SANTOS, N.M.; MEDEIROS, A.N. et al. Buchada caprina: características físico-químicas e microbiológicas. Campina Grande: Editora Impressos Adilson, 2007. 93p.

FERREIRA, M.A.; VALADARES FILHO, S.C.; MUNIZ, E.B. et al. Características das carcaças, biometria do trato gastrintestinal, tamanho dos órgãos internos e conteúdo gastrintestinal de bovinos F1 Simental x Nelore alimentados com dietas contendo vários níveis de concentrado. Revista Brasileira de Zootecnia, v.29, n.4, p.1174-1182, 2000.

FRASER, A.; STAMP, J.T. Ganado ovino: producción y enfermedades. Madri: Ediciones Mundi-Prensa, 1989. 328p.

FURLAN, R.L.; MACARI, M.; FARIA FILHO, D.E. Anatomia e fisiologia do trato gastrintestinal. In: BERCHIELLI, T.T.; PIRES, A.V.; OLIVEIRA, S.G. (Eds.) Nutrição de ruminantes. Jaboticabal: Funep, 2006. p.1-23.

GASTALDI, K.A.; SILVA SOBRINHO, A.G.; MACHADO, M.R.F. et al. Proporção dos componentes não constituintes da carcaça em cordeiros alimentados com dietas com diferentes relações volumoso:concentrado e abatidos aos 30 ou $34 \mathrm{~kg}$ de peso vivo. In: REUNIÃO ANUAL DA SOCIEDADE BRASILEIRA DE ZOOTECNIA, 38., 2001, Piracicaba. Anais... Piracicaba: SBZ, 2001. p.956-957.

JENKINS, T.C. Lipid metabolism in the rumen. Journal of Dairy Science, v.76, n.12, p.3851-3863, 1993.

KAMALZADEH, A.; KOOPS, W.J.; VAN BRUCHEM, J. et al. Feed quality restriction and compensatory growth in growing sheep: development of body organs. Small Ruminant Research, v.29, p.71-82, 1998

KOZLOSKI, G.V. Bioquímica dos ruminantes. Santa Maria: Universidade Federal de Santa Maria, 2002. 140p.

MEDEIROS, G.R.; CARVALHO, F.F.R.; FERREIRA, M.A. et al. Efeito dos níveis de concentrado sobre os componentes nãocarcaça de ovinos Morada Nova em confinamento. Revista Brasileira de Zootecnia, v.37, n.6, p.1063-1071, 2008.

MENDES, C.Q.; SUSIN, I.; PIRES, A.V. et al. Desempenho, parâmetros da carcaça e comportamento ingestivo de cordeiros alimentados com cana-de-açúcar ensilada ou in natura. Arquivo Brasileiro de Medicina Veterinária e Zootecnia, v.60, n.3, p.733-740, 2008.
MORENO, G.M.B.; SILVA SOBRINHO, A.G.; LEÃO, A.G. et al. Rendimentos de carcaça, composição tecidual e musculosidade da perna de cordeiros alimentados com silagem de milho ou canade-açúcar em dois níveis de concentrado. Arquivo Brasileiro de Medicina Veterinária e Zootecnia, v.62, n.3, p.686-695, 2010.

MORON-FUENMAYOR, O.E.; CLAVERO, T. The effect of feeding system on carcass characteristics, non-carcass components and retail cut percentages of lambs. Small Ruminant Research, v.34, n.1, p.57-64, 1999.

NATIONAL RESEARCH COUNCIL - NRC. Nutrient requirements of dairy cattle. 6.ed. Washington: National Academy of Sciences, 1989. 158p.

NATIONAL RESEARCH COUNCIL - NRC. Nutrient requirements of sheep. New York: National Academy Press, 1985. 99p.

OKAMOTO, F.; CUNHA, E.A.; BUENO, M.S. et al. Desempenho de borregas da raça Santa Inês alimentadas com cana-deaçúcar e ramas de amoreira. Boletim da Indústria Animal, v.65, n.1, p.1-6, 2008.

OSÓRIO, J.C.S. Estudio de la calidad de canales comercializadas em el tipo ternasco segun la procedencia: bases para la mejora de dicha calidad em Brasil. 1992. 335f. Tese (Doutorado em Veterinaria) - Facultad de Veterinaria, Universidad de Zaragoza, Zaragoza.

PÉRON, A.J.; FONTES, C.A.A.; LANA, R.P. et al. Tamanho dos órgãos internos e distribuição da gordura corporal em novilhos de cinco grupos genéticos, submetidos à alimentação restrita e ad libitum. Revista Brasileira de Zootecnia, v.22, n.5, p.813-819, 1993.

SANTOS, N.M.; COSTA, R.G.; MEDEIROS, A.N. et al, Caracterização dos componentes comestíveis não constituintes da carcaça de caprinos e ovinos. Agropecuária Técnica, v.26, n.2, p.77-85, 2005.

SAÑUDO, C.; SIERRA, I. Calidad de la canal en la especie ovina. Ovino, v.11, n.1, p.127-153, 1986.

SIQUEIRA, E.R.; SIMÕES, C.D.; FERNANDES, F. Efeito do sexo e do peso ao abate sobre a produção de carne de cordeiro, morfometria da carcaça, pesos dos cortes, composição tecidual e componentes não constituintes da carcaça. Revista Brasileira de Zootecnia, v.30, n.4, p.1299-1307, 2001.

STATISTICAL ANALYSIS SYSTEM - SAS. User's guide. Cary: SAS Institute Inc., 1996. 1200p.

YAMAMOTO, S.M.; MACEDO, F.A.F.; MEXIA, A.A. et al. Rendimento de cortes e não-componentes das carcaças de cordeiros terminados com dietas contendo diferentes fontes de óleo vegetal. Ciência Rural, v.34, n.6, p.1909-1913, 2004. 